\section{AB1229 \\ ASSESSMENT OF ENTHESITIS BY ULTRASONOGRAPHY IN PATIENTS WITH SERONEGATIVE RHEUMATOID ARTHRITIS}

Z. Erturk' ${ }^{1}$, T. Ozsoy ${ }^{2}$, I. Yagci' ${ }^{2}$, Y. Yalçınkaya ${ }^{1}$, Ü. Gazel ${ }^{1}$, P. Atagündüz ${ }^{1}$, H. Direskeneli ${ }^{1}$, N. Inanç ${ }^{1} .{ }^{1}$ Rheumatology; ${ }^{2}$ Physical Therapy and Rehabilitation, Marmara University School of Medicine, Istanbul, Turkey

Background: In patients with seronegative rheumatoid arthritis (RA) there is a difficulty to make the differential diagnosis with the spondyloarthropathies.

Objectives: To assess the presence of enthesitis in patients with seronegative RA in comparison with the healthy controls $(\mathrm{HC})$, patients with seropositive RA and ankylosing spondylitis(AS).

Methods: In this cross-sectional study, seronegative and seropositive RA patients, who fulfilled the 2010 ACR/EULAR criteria, patients with AS and HC have been assessed by grey scale and power doppler ultrasonography for the presence of enthesopathy at the achilles tendon, plantar fascia, proximal patella, distal patella, quadriceps, tibialis anterior, triceps, common flexor and extensor tendons. Clinical assessment of the patient groups included demographic findings, health assessment questionnaire and DAS28.

Results: In our study, we recruited age and sex matched 27 seronegative RA, 19 healthy controls, 24 seropositive RA and 23 ankylosing spondylitis patients. We evaluated and analysed both right and left sides of the enthesis regions separately which have been indicated in the methods section. The mean DAS28, mean ESR and mean CRP of the patients with seronegative RA were $3.6 \pm 1.28,32.2$ \pm 21.2 and $12.37 \pm 27.77$ respectively (table 1 ).

Median of Madrid sonographic enthesitis index (MASEI) was 5 in patients with seronegative RA. 4 patients have severe scores (MASEl score $>20$ ). There were significant differences between seronegative RA and healthy controls (MASEI score:3), ( $\mathrm{p}=0.014)$ but no differences has been observed between seronegative RA with seropositive RA (MASEI score:6) and anklosing spondylitis (MASEI score:7) in MASEI scores.

In comparison, hypoechogenicity of quadriceps tendon (16 (29.6\%) vs $6(12.5 \%)$, $\mathrm{p}=0.037$ ), bone erosion at the quadriceps tendon attachment $(9(16.6 \%)$ vs 0 , $\mathrm{p}=0.003)$, calsification at achilles tendon $(17(31.4 \%)$ vs $6(12.5 \%), \mathrm{p}=0.023)$ have been observed more frequently in patients with seronegative RA than seropositive RA. Significantly higher number of patients with bone erosion at the common extansor tendon $(26(48.1 \%)$ vs $3(6.5 \%), p=<0.001)$, calsification at achilles tendon (17 (31.4\%) vs $2(4.3 \%), p=0.024)$, erosion at triceps tendon (13 $(24 \%)$ vs 1 $(2.1 \%), p=0.035)$ have been detected in patients with ankylosing spondylitis than seronegative RA (table 2).

\begin{tabular}{|c|c|c|c|c|}
\hline & $\begin{array}{c}\text { Seronegative } \\
\text { RA }\end{array}$ & $\begin{array}{c}\text { Healthy control } \\
\text { group }\end{array}$ & $\begin{array}{c}\text { Seropositive } \\
\text { RA }\end{array}$ & $\begin{array}{l}\text { Ankylosing } \\
\text { spondylitis }\end{array}$ \\
\hline Age, years & $51,85 \pm 11,49$ & $46,2 \pm 6,6$ & $53,12 \pm 10,95$ & $43,75 \pm 4,1$ \\
\hline Women, n (\%) & $48(88,9)$ & $38(100)$ & $44(91,7)$ & $38(82,6)$ \\
\hline RA duration, year & $9,8 \pm 6,75$ & NA & $12,29 \pm 9,3$ & NA \\
\hline RF titre, median & $10,77 \pm 3,21$ & NA & $\begin{array}{c}323,68 \\
\pm 372,72\end{array}$ & NA \\
\hline $\begin{array}{l}\text { AntiCCP titre, } \\
\text { median }\end{array}$ & $3,99 \pm 4,13$ & NA & $\begin{array}{c}300,16 \\
\pm 264,93\end{array}$ & NA \\
\hline DAS28, median & $3,6 \pm 1,28$ & NA & $3,73 \pm 1,45$ & NA \\
\hline ESR, median & $32,2 \pm 21,2$ & NA & $38,73 \pm 26,88$ & $38,72 \pm 9,16$ \\
\hline CRP, median & $12,37 \pm 27,77$ & NA & $12,73 \pm 18,57$ & $10,38 \pm 9,3$ \\
\hline
\end{tabular}

Abstract AB1229 - Table 2. Assessing patients with seronegative rheumatoid arthritis about enthesopathy by ultrasound- Pathological findings

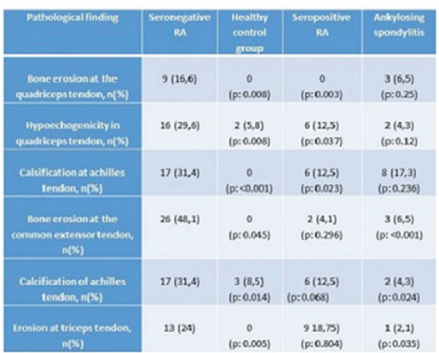

Conclusions: We observed that enthesis involvement was not seldom in patients with seronegative RA. Furthermore there were also similar frequency of entesis involvement in seropositive patients with RA. The value of enthesis sites evaluation for the differential diagnosis of patients with seronegative RA should be further investigated and the assessment of enthesis sites in seronegative and seropositive RA patients can be important to detect active and chronic changes at the enthesis region.
Disclosure of Interest: None declared

DOI: 10.1136/annrheumdis-2018-eular.4016

\section{Public health, health services research and health economics}

\section{AB1230 PATIENT EMPOWERMENT THROUGH THE USE OF A MOBILE PHONE APPLICATION: THE EXPERIENCE OF RHEUMABUDDY IN ITALY}

A. Alunno $^{1}$, L. Andreoli ${ }^{2}$, L. Quartuccio ${ }^{3}$, F. Carubbi ${ }^{4,5}$, on behalf of the Italian Society of Rheumatology Committee for young rheumatologists (SIRyoung). ${ }^{1}$ Department of Medicine, Rheumatology Unit, University of Perugia, Perugia; ${ }^{2}$ Department of Clinical and Experimental Sciences, Rheumatology and Clinical Immunology, Spedali Civili and University of Brescia, Brescia; ${ }^{3}$ Department of Medical and Biological Sciences, Rheumatology Clinic, Azienda OspedalieroUniversitaria 'S. Maria della Misericordia', Udine; ${ }^{4}$ Department of Biotechnological and Applied Clinical Sciences, Rheumatology Unit, University of L'Aquila;

${ }^{5}$ Department of Medicine, ASL 1 Avezzano-Sulmona-L'Aquila, L'Aquila, Italy

Background: Patient education and empowerment are cornerstones in the management of rheumatic and muscoloskeletal diseases (RMDs). In fact, they improve the physician-patient relationship and ensure a successful shared decision making process. In recent years, the esponential growth of interactive media and the progress of technology led to the parallel development of digital healthcare and the evaluation of how tools like mobile applications (app) can contribute to patient empowerment. Rheumabuddy has been developed thanks to the collaboration of the Danish association of young patients with RMDs (FNUG) and a Danish agency specialised in digital heathcare (Daman). RheumaBuddy is designed for young patients (18-35 years old) with chronic arthritis and integrates the function of a diary to monitor the main features of the disease (e.g. pain, stiffness, fatigue) and a forum to interact with other users and provide mutual help.

Objectives: We aimed at developing the Italian version of RheumaBuddy to make it available to Italian patients with RMDs.

Methods: The Italian Society of Rheumatology Committee for young rheumatologists (SIRyoung) translated the content of the app from English to Italian adapting when needed because of language incompatibility.

Results: The Italian version of RheumaBuddy was launched on the 12th Octobe 2017 (World Arthritis Day) in partnership with national patient associations (ANMAR and APMAR). The app was also presented via a press release from the Italian Society of Rheumatology. To date, RheumaBuddy was downloaded by 1182 users with 822 of them currently using the app on a regular basis. The feedback collected so far highlighted the usefulness of the app and pointed out potential weaknesses and issues to be tailored to the Italian population. The gathering of feedback from users is still ongoing.

Conclusions: We developed the Italian version of RheumaBuddy, which is currently used by a consistent number of young patients with chronic arthritis. A board including patient representatives, rheumatologists and the app developers will be established to specifically tailor the app according to the needs and priority of Italian users and based on the feedback collected.

Disclosure of Interest: None declared

DOI: 10.1136/annrheumdis-2018-eular.4229

\section{$\mathrm{AB} 1231$ \\ EFFICACY AND COST ANALYSIS OF A SYSTEMATIC SWITCH FROM ORIGINATOR INFLIXIMAB TO BIOSSIMILAR CT-P13 OF ALL PATIENTS WITH INFLAMMATORY ARTHRITIS FROM A SINGLE CENTRE}

A. Valido ${ }^{1}$, J. Silva-Dinis ${ }^{1,2}$, M.J. Saavedra ${ }^{1,2}$, N. Bernardo ${ }^{3}$, J.E. Fonseca ${ }^{1,2}$. ${ }^{1}$ Rheumatology, Hospital Santa Maria - CHLN; ${ }^{2}$ Rheumatology Research Unit, Instituto de Medicina Molecular, Faculty of Medicine, University of Lisbon; ${ }^{3}$ Trading unit - Purchasing management service, Hospital Santa Maria - CHLN, lisbon, Portugal

Objectives: The aim of this study was to analyse efficacy, safety and cost sav ings of switching from infliximab originator (IFXor) to the biosimilar (BS) CT-P13 in single centre.

Methods: Eligible patients were those older than 18 years old with the diagnosis of rheumatoid arthritis (RA), spondylarthritis (SpA) and psoriatic arthritis (PsA) on treatment (Tx) with IFXor for at least 6 months and with stable disease activity. In December 2016 all eligible patients were proposed to switch to CT-P13. At the day of the last Tx with IFXor, informed consent, data and blood samples were collected. On the next Tx day, CT-P13 was administered after standard evaluation of efficacy and safety. Efficacy was measured considering change from baseline in Disease Activity Score in 28 joints (DAS28) for RA and PsA and in Ankylosing Spondylitis Disease Activity Score (ASDAS) for SpA. Disease worsening was 
considered when an increase of 1.2 from baseline in DAS28 or an increase of 1.1 in ASDAS occurred. A cost analysis was done based on the purchasing prices of the 2 drugs at our centre.

Results: In a 12 months period switch to CT-P13 was performed in 60 patients for non-medical reasons. Disease activity (DA) was stable over the observation period and similar to the values observed with IFXor. Median follow-up time was 261 days during which disease worsening occurred in $3(5 \%)$ patients. 1 patient had a minor adverse event (oedema of the lip). These $4(6.7 \%)$ patients stopped the BS. One returned to IFXor and the other 3 switched to another drug. The switch to CT-P13 represented a $26.4 \%$ reduction of costs in the use of IFX Tx in these patients.

Abstract AB1231 - Table 1. Numbers are medians unless otherwise stated.

\begin{tabular}{lcccc}
\hline & $\begin{array}{c}\text { Total } \\
(\mathrm{n}=60)\end{array}$ & $\begin{array}{c}\text { SpA }(\mathrm{n}=36 ; \\
60 \%)\end{array}$ & $\begin{array}{c}\text { RA }(\mathrm{n}=16 ; \\
27 \%)\end{array}$ & $\begin{array}{c}\text { PA }(\mathrm{n}=8 ; \\
13 \%)\end{array}$ \\
\hline Age (years) & $53(48-$ & $50(41-59)$ & $59(52-70)$ & $56(48-64)$ \\
& $64)$ & & & \\
Gender (n,\% male) & $39(65 \%)$ & $30(83 \%)$ & $2(13 \%)$ & $7(88 \%)$ \\
Disease duration (years) & $17(10-$ & $16(10-22)$ & $18(13-24)$ & $16(10-22)$ \\
& $23)$ & & & \\
Patients on methotrexate & $41(68 \%)$ & $20(33 \%)$ & $15(25 \%)$ & $6(10 \%)$ \\
Patients with previous biologic & $4(6.7 \%)$ & $1(2.8 \%)$ & $3(18.8 \%)$ & $0(0 \%)$ \\
therapy & & & & \\
Time on IFX originator before & $7.9(6.5-$ & $7.7(6.4-$ & $8.4(6.7-$ & $7.6(6.7-$ \\
switch (years) & $11.9)$ & $12.3)$ & $12.4)$ & $9.6)$ \\
$\begin{array}{l}\text { Time on CT-P13 since switch } \\
\text { (months) }\end{array}$ & $9(7-11)$ & $9(7-11)$ & $10(9-10)$ & $9(4-10$ \\
\hline
\end{tabular}

Abstract AB1231 - Table 2. Variables median from baseline to 9 months after switch to CT-P13. ESR - Erythrocyte Sedimentation Rate; CRP - C-Reactive Protein; PtGA - Patien global assessment of DA; PhGA - Physician global assessment of DA.

\begin{tabular}{|c|c|c|c|c|c|}
\hline & Baseline & $\begin{array}{l}3 \text { Months } \\
\text { after } \\
\text { switch }\end{array}$ & $\begin{array}{c}6 \text { Months } \\
\text { after } \\
\text { switch }\end{array}$ & $\begin{array}{c}9 \text { Months } \\
\text { after } \\
\text { switch }\end{array}$ & $\begin{array}{l}\text { Variation from baseline } \\
\text { to } 9 \text { Months after switch }\end{array}$ \\
\hline $\begin{array}{l}\text { ESR } \\
(\mathrm{mm} / \mathrm{h})\end{array}$ & $\begin{array}{c}15(10- \\
21)\end{array}$ & 17 (9-29) & $15(9-24)$ & $15(9-24)$ & 0 \\
\hline $\begin{array}{l}\text { CRP } \\
\text { (mg/ } \\
\text { dL) }\end{array}$ & $\begin{array}{c}0.18 \\
(0.80- \\
0.57)\end{array}$ & $\begin{array}{c}0.17(0.06- \\
0.50)\end{array}$ & $\begin{array}{c}0.19(0.10- \\
0.46)\end{array}$ & $\begin{array}{c}0.25(0.10- \\
0.72)\end{array}$ & 0.07 \\
\hline $\begin{array}{l}\text { PtGA } \\
(0-100)\end{array}$ & $\begin{array}{c}30(20- \\
50)\end{array}$ & $20(30-50)$ & $30(3-50)$ & $30(15-50)$ & 0 \\
\hline $\begin{array}{l}\text { PhGA } \\
(0-100)\end{array}$ & $\begin{array}{c}20(10- \\
30)\end{array}$ & $20(10-30)$ & $20(0-30)$ & $20(10-30)$ & 0 \\
\hline
\end{tabular}

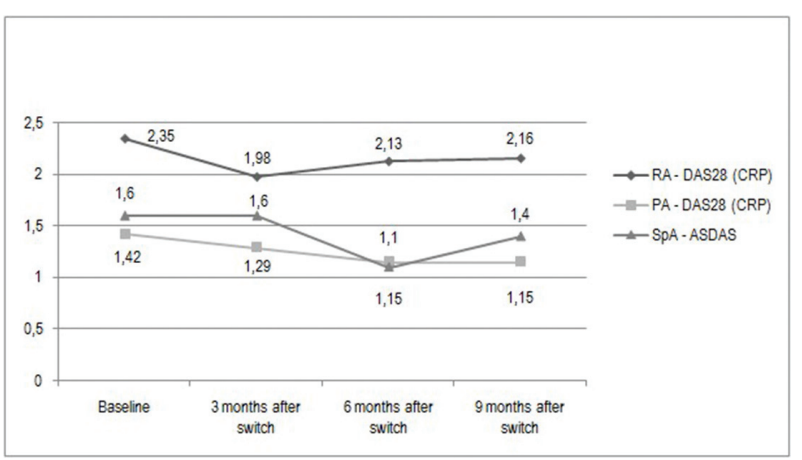

Abstract AB1231 - Figure 1

Conclusions: The switch in routine care of a group of RA, SpA and PsA patients from IFXor to CT-P13 did not affect efficacy and safety and reduced costs in $26.4 \%$.

\section{REFERENCE:}

[1] Bente Glintborg, et al. A nationwide non-medical switch from originator infliximab to biosimilar CT-P13 in 802 patients with inflammatory arthritis: 1-year clinical outcomes from the DANBIO registry. Ann Rheum Dis 2017;0:1-6.

Disclosure of Interest: None declared DOI: 10.1136/annrheumdis-2018-eular.5844

\section{$\mathrm{AB} 1232$ \\ ESTIMATING THE ECONOMIC VALUE OF A PATIENT SUPPORT PROGRAM IN RHEUMATOID ARTHRITIS IN THE UNITED KINGDOM}

A. Ostor ${ }^{1}$, V. Garg ${ }^{2}$, M. Yang ${ }^{3}$, C. Chamberlain ${ }^{4}$, M. Skup $2 .{ }^{1}$ Cabrini Medical Centre, Melbourne, Australia; ${ }^{2}$ AbbVie, Chicago; ${ }^{3}$ Analysis Group, Inc; ${ }^{4}$ Analsysis group, Inc., Boston, USA

Background: A Patient Support Program (PSP) offered by AbbVie to adalimumab-treated patients assists them with issues pertaining to medication costs, nurse support, injection training, pen disposal, and medication reminders. A num ber of studies have reported the benefit of enrollment in this PSP from different perspectives, including clinical, patient-reported, and adherence outcomes. ${ }^{1-2}$ There is limited information available on the economic value of the PSP

Objectives: To estimate the incremental economic value associated with enrollment in the PSP for adalimumab-treated patients with rheumatoid arthritis (RA) from a UK societal perspective.

Methods: An Excel-based economic model was developed to describe adalimu mab-treated PSP enrollees over non-enrollees in terms of a) improvement in clinical status as measured by the Health Assessment Questionnaire Disability Index (HAQ-DI], which resulted in reduced healthcare resource utilisation (HRU), and b) improvement in work productivity as measured by the Work Productivity and Activity Impairment Questionnaire (WPAI). The associated incremental direct and indirect cost savings were estimated over a 12 month period. Scores on HAQ-DI, work productivity impairment, and employment rate were obtained from a prospective, observational Phase IV study assessing patient satisfaction and outcomes in the context of the PSP (AbbVie Care) among RA patients (NCT01383421, PASSION) ${ }^{1}$. Inputs from literature and UK-specific publically available sources were used to model the association between HAQ-DI score cat egories $(0-<0.6,0.6-<1.1,1.1-<1.6,1.6-<2.1,2.1-3)$ and HRU among RA patients, and to obtain unit costs of HRU (i.e., hospitalizations, specialist visits imaging assessments) and weekly work compensation.

Results: In PASSION, a greater proportion of PSP enrollees were in the lower HAQ-DI categories (i.e., better outcomes) and enrollees had greater reduction in total work impairment than non-enrollees after treatment with adalimumab. Assuming a population of 10000 adalimumab-treated RA patients in the UK, this was associated with an incremental annual cost saving of $£ 2,320,809$ should all these patients enrol in the PSP. The largest proportion of incremental cost saving resulted from the reduction in RA-related hospitalizations ( $£ 1,550,637 ; 66.8 \%$ ). Cost saving due to improved work productivity accounted for the second largest proportion (£686,963,29.6\%). Specialist visits and imaging assessments accounted for $1.9 \%(£ 44,564)$ and $1.7 \%(£ 38,645)$ of the total incremental cost saving, respectively.

Conclusions: Enrollment in AbbVie's PSP was shown to be associated with incremental cost saving among adalimumab-treated RA patients due to reduced resource utilisation and improved work productivity.

\section{REFERENCES:}

[1] van Den Bosch F, et al. Rheumatol Ther. 2017;4:85-96.

[2] Rubin DT, et al. J Manag Care Spec Pharm. 2017;23(8):859-867.

Acknowledgements: Medical writing support was provided by Cheryl Q. Xiang of Analysis Group; this support was funded by AbbVie.

Disclosure of Interest: A. Ostor Grant/research support from: Roche, Chugai, MSD, AbbVie, Pfizer, Novartis, Napp, Janssen, Lilly and BMS, Consultant for: Roche, Chugai, MSD, AbbVie, Pfizer, Novartis, Napp, Janssen, Lilly and BMS, V. Garg Shareholder of: AbbVie, Employee of: AbbVie, M. Yang Employee of: Analysis Group, Inc., which has received consultancy fees from AbbVie, C. Chamberlain Employee of: Analysis Group, Inc., which has received consultancy fees from AbbVie, M. Skup Shareholder of: AbbVie, Employee of: AbbVie DOI: 10.1136/annrheumdis-2018-eular.5685

\section{AB1233 DOES TIME MATTER? A SYSTEMATIC REVIEW TO ASSESS THE RELATIONSHIP BETWEEN DELAY IN DIAGNOSIS AND COSTS IN DMARD-NAÏVE RA PATIENTS}

I. Sahbudin ${ }^{1,2}$, R. Singh ${ }^{1,2}$, J. Trickey ${ }^{2}$, A. Tracy ${ }^{3}$, K. Raza $^{2,3}$, A. Filer $^{1,2}$, A. Boonen ${ }^{4}$. ${ }^{1}$ Department of Rheumatology, University Hospitals Birmingham NHS Foundation Trust, Queen Elizabeth Hospital Birmingham; ${ }^{2}$ Rheumatology Research Group, Institute of Inflammation and Ageing, University Hospitals of Birmingham; ${ }^{3}$ Department of Rheumatology, Sandwell and West Birmingham Hospitals NHS Trust, Birmingham, UK; ${ }^{4}$ Maastricht University Medical Center and Caphri Research Institute, Maastricht University, Maastricht, Netherlands

Background: Early diagnosis is crucial to enable timely DMARDs initiation in RA patients. Although, early treatment improves clinical outcomes, it is unclear whether this has a similar impact on health economic outcomes. Early DMARDs 